\title{
The Lack of Qualified EFL Teachers in Saudi Schools: A Qualitative Interview Study
}

\author{
Abdullah N Alqahtani ${ }^{1}$ \\ ${ }^{1}$ College of Science and Humanities, Prince Sattam Bin Abdulaziz University, Al-Kharj, Saudi Arabia \\ Correspondence: Abdullah N Alqahtani, College of Science and Humanities, Prince Sattam Bin Abdulaziz \\ University, Al-Kharj, Saudi Arabia. E-mail: anq1@outlook.sa
}

Received: August 23, 2021

Accepted: October 8, $2021 \quad$ Online Published: October 13, 2021

doi: $10.5539 /$ elt.v14n11p24

URL: https://doi.org/10.5539/elt.v14n11p24

\begin{abstract}
Despite teaching English language in Saudi Arabia for 6 decades, yet the outcomes are unsatisfactory. In this article, the lack of qualified English teachers in Saudi Arabia is the main reason for causing that issue. To address the issue, this study attempts to understand how untrained teachers have a negative influence on students' performance and competence. Unstructured interviews were conducted with students from two Saudi schools to reflect on the problems and obstacles that Saudi pupils encounter as a result of their incompetent instructors. Instead of interviewing instructors, we interviewed students to know the strategies, methods, and techniques employed by their teachers, which resulted in their incapacity to improve. According to the participants, the majority of English teachers in Saudi schools speak Arabic in English lessons rather than English. They also employ traditional approaches such as the teacher-centered method. They educate and explain in English, but when they reach a major obstacle, they immediately switch to Arabic as an efficient option. The study's findings highlight the necessity of having trained teachers to teach English in EFL programs in Saudi Arabia. The study's objective is to demonstrate that instructors are at the heart of the issues that affecting students' growth and how to assist them to overcome those problems.
\end{abstract}

Keywords: EFL learners, EFL teachers, teacher education, teacher pre-service training

\section{Introduction}

English language is one of the important languages around the world. Every day the importance of English is increasing according to various reasons. In addition to that, to understand the world in simple way, we should have enough practice and experience in English. Nowadays, English language almost always has become necessary for all the aspects of education, trading, medical needs, politics, etc. Moreover, In Saudi Arabia, teaching English language is the main target of the Ministry of Education. The government of Saudi Arabia has facilitated everything about teaching English language for the Saudi students in order to have golden outcomes. In addition, English language has been teaching in Saudi Arabia for almost 60 years, yet the outcomes are not acceptable compared to the efforts that have had made. In Saudi Arabia, we have good schools, well prepared classes, and academic curriculums, yet we do not have qualified teachers for teaching English language. We believe that teachers are the core of any learning processing and without having qualified teachers, the teaching processing will be failed. This research aims to prove that despite of all the arrangements that have made to teach English in Saudi schools, yet the results are not satisfied for the Ministry of Education.

\subsection{Statement of The Problem}

The majority of Saudi students cannot speak English language because of the lack of qualified teachers. The English teachers in Saudi schools are still using the old/classical methods for teaching English. For example, they use the mother tongue for teaching English most of the time. They teach English through grammar and translate often word by word from English to Arabic. They think that the grammar and the translation of words can be enough for the Saudi students to speak and understand English. They use methods where the teachers are active, while the students are passive (Teacher-Centered Approach to Learning). In other words, students receive the knowledge from their lectures passively not actively which affects the process of learning. Furthermore, it is important to mention that the Saudi graduated students from high schools cannot speak and write English because of the way they have been learned English. It is a fact that the Saudi students of all grades are encountering challenges and difficulties to learn English. Several studies of learning and teaching English such 
as (Al-Seghayer, 2014; Al-Sobhi \& Preece, 2018; Elyas \& Mahboob, 2014; Hamad, 2013) have showed that the Saudi students face real problems not only in speaking skills, but also in the four basic skills. These studies showed that the Saudi students lost their ambitions and motivations to learn English language. However, in this research, we believe that if the teachers are qualified, the consequences will be satisfied.

\subsection{Research Significance}

This present paper will be valuable to those who are interested in the field of language teaching and learning. This research aims to show how teachers in Saudi Arabia filed to teach English for decades. This article focuses on how unqualified teachers affect the students' way of learning. On the other hand, this research aims to help teachers to improve their skills in language teaching. It provides effective methods of teaching that can help the students to learn English in an appropriate way. This paper shows how teachers can replace classical methods with effective methods.

\subsection{Research Objectives}

The objectives of this article are to:

1) Raise the Saudi teachers' awareness about alternative methods to improve their skills in teaching. Raise the Saudi teachers' awareness about alternative methods to improve their skills in teaching.

2) Help the Saudi teachers to understand that old/classical methods in teaching are not effective.

3) Motivate the Saudi teachers to take their responsibilities in right way.

4) Advise the Saudi teachers to teach English through the four basic skills in general, and through speaking and listening skills in particular in order to have real outcomes.

5) Help the Saudi students to learn English in an effective way through multiple techniques and strategies.

\subsection{Research Questions}

This paper is organized to give answers and advices to the following questions:

1) What are the reasons that affect the Saudi students' performance in English language?

2) What are the alternative methods that Saudi teachers should use in classes instead of the old methods?

3) What should the ministry of education in Saudi Arabia do to help the Saudi English teachers to overcome their weaknesses?

4) Why the majority of Saudi students in universities still cannot even speak and write simple English?

\subsection{Research Hypotheses}

It is hypothesized that

1) The majority of Saudi English teachers use Arabic to teach English.

2) Saudi teachers teach English through grammar and word by word methods.

3) Saudi teachers ignore listening and speaking skills in classrooms and focus more on writing and reading.

4) Most of the Saudi English teachers are not aware of new and effective methods of teaching.

5) Saudi students are victims of old methods that have been used for decades.

6) Saudi students cannot read or write simple statements of English because they have used to focus on the grammar and the meaning of words.

\section{Literature Review}

Researchers have treated teaching English for second language learners in much detail, but previous studies have not dealt with teachers' effect on the environment of teaching. Furthermore, most of the studies in the field of teaching have aimed on the problems that related to the methods or curriculums. However, there has been little discussion about teachers' abilities and responsibilities. In this paper, I argue that the unsatisfied outcomes of teaching English in the Saudi schools are in the first place because of the teachers' performance and competence. Therefore, the purpose of this study is to shine new light on these problems and try to control and overcome them. 


\subsection{The Importance of English Language}

Nowadays, English language cannot be ignored for any reason. The importance of learning and teaching English language is increasing day by day. English is fast becoming a key instrument for education, sciences, medicine, sports, tourism, etc. In addition to that, English is one of the most widely used language around the world, it is increasingly recognized as an important role for communication. In Saudi Arabia, English is a fundamental aspect of the Saudi Arabia 2030 vision. The Saudi Ministry of Education has announced that in 2021, English language will be taught from the grade one of primary schools. This movement shows us the importance of English as a fundamental aspect that cannot be ignored.

\subsection{Teachers and Old Teaching Methods}

Teacher is an important component in the teaching system, and plays a key role in students' development. All the obstacles in education can be overcome during the time, but having unqualified teachers in schools will cost damage for years on the students' performance and competence in English language. One of major problems of Saudi English teachers is using mother tongue to teach English, and sometimes explain English with Arabic accent. One study found out that "the Arabic and English phonological systems are very different, not only in the range of sounds used, but in the emphasis placed on vowels and consonants" (Swan \& Smith, 2001, p. 195). In addition to that, most studies in the field of teaching have only focused on teaching methods, strategies, curriculums, etc. However, this paper aims to prove that the weaknesses of Saudi English teachers cost damage to the Saudi learners. Therefore, the competence and performance of teachers should be taken in consideration. In Saudi Arabia, the majority of English teachers for all grades are still unqualified, therefore the outcomes are not satisfied. On the other hand, there are old methods and techniques of teaching that still used in Saudi schools as essential way of teaching. For example, the Grammar Translation Method; this method is depending on the teacher's performance. The teacher is active but the students are almost always passive. In this method, classes are taught in the students' mother tongue. Therefore, students are facing two main problems; the lack of qualified teachers, and old methods are existed. A research found out that "the traditional methodology puts the responsibility for teaching and learning mainly on the teacher and it is believed that if students are present in the lesson and listen to the teacher's explanations and examples, they will be able to use the knowledge" (Boumová, 2008, p. 11). Therefore, teachers focus on the knowledge of a particular topic in the curriculum, but ignore the performance of the students. In addition to that, a number of studies found out that in old/traditional teachinhg methods teachers ignore the basic skills, speaking and writing, listening and reading (Boumová, 2008).

\subsection{L1 Influence on Teaching English}

It is fact that most of the teachers around the world use mother tongue consciously or unconsciously to teach any second language. Therefore, this influence can lead to negative consequences not only on the students' outcomes but also their instructors. In addition to that, using mother tongue (Arabic) to teach English will affect students' performance negatively. Furthermore, teachers think that using the mother tongue will facilitate the course to the students. For example, teaching grammars in English language to the student by using Arabic language. Therefore, students will be weak in listening and speaking, because if the students are weak in listening, they will be weak in speaking either. In this regard, using the mother tongue to teach any aspect of English in classrooms will limit the students' progress.

\subsection{Lack of Exposure to English}

It is obvious that learning English in an English environment will help the students to learn the language faster. In other words, when a student is surrounding by English, his/her level in a language will be high. Additionally, one study stated out that "the environment plays an influential role in developing a learner's language" (Al-Sobhi \& Preece, 2018, p. 2). On the other hand, most of the Saudi English teachers have learned English in Saudi Arabia. Therefore, their competence, performance, and skills are not convincing. Furthermore, they cannot be aware of the new and effective methods in teaching. In fact, Saudi English teachers lost their motivation in teaching and follow the classical way of teaching to avoid any embarrassing situations. Therefore, the Saudi students are not able to exposure the English language because they live in an Arabian environment. Moreover, the Saudi students also face a prominent challenge which is the environment. This permanently challenge will affect their progress. In fact, the teachers did not exposure enough English, therefore, their students will not exposure enough English. On the other hand, both teachers and students in Saudi schools are not aware of the importance and value of English language. The reason behind that is again the environment. For example, they do not need to use English to communicate, shopping, ordering food, etc. All their needs can be done by using Arabic language. Therefore, it is teachers' responsibility to show the value of learning English language and how it is important to their future. 


\subsection{Alternative/Effective Methods in Teaching}

Teachers should be aware of new and effective methods of teaching. They should think of a particular method based on the students' level. In addition to that, methods of teaching in primary levels will be completely different from middle and high levels. Teachers who teach primary classes should use methods that motivate the students to participate the class. For example, Audio-Lingual Method, this method is about using dialogues to improve students' performance in listening and speaking. It based on repetition for pattern drills for several times to give the students the confidence to speak. Pictures are also used in this method to teach new words, instead of saying the meaning of the word by explaining its equivalent in Arabic. Therefore, a teacher will show some pictures such as lion, sea, sun, horse, house, etc. After that, he or she will show any picture then asks the students to repeat after him or her. This process of this method has to be started and ended by the target language. This method is truly effective because the students will make strong correlation between the picture and meaning. By the end of the class, students will gain new word, particular pronunciation, and strong correlation between them. Moreover, it is highly important to mention that the English should be taught to the students with fun in order to reach wonderful results. On the other hand, for middle and high levels classes, teachers should be aware that in this age, most of the students will not be willing to participate the class. Therefore, most of the efforts will be on the teachers. In addition to that, listening to short audio stories or short conversation will help the students to recognize words and their pronunciation. Teachers can also ask the students to make themselves as groups, each group will contain five students, and each group will have a task to deal with. This cooperative learning technique will encourage the students to speak English regardless the difficulty of the task. Furthermore, one of the effective techniques is to ask the students to do presentation about a particular topic by using English. This technique will enhance students' performance, competence, and confidence. In addition to that, for middle and high schools, there are some effective methods that teachers should use. For example, Direct Method, this method is considered as a revolutionary method to The Grammar Translation Method. All the principles and techniques between these two methods are different. This method does not allow the teachers to use the native language under any circumstances. The goal of this method is to help the students to speak and think in the target language. In this method, mistakes are acceptable for the students. However, teachers should correct mistakes indirectly way in order to encourage the students for participation and to help the to overcome their weaknesses. Furthermore, Community Language Learning Method; this method is also one of the effective methods because both teachers and students are active. In this method, teachers should build relationship between the students by asking them to group themselves to have real conversation based on the class's topic. The goal of this method is that language is for communication. However, this method needs qualified teachers because it needs techniques to reach the goals. It is important to mention that this method may allow the students to use the mother tongues only in writing skill to write the meaning of words. Also, this method can only be used with adults because of its learning procedures.

\section{Methodology}

In this research, we conducted interviews with students not teachers. The reason behind this is that the teachers may avoid direct answers to cover their mistakes and weaknesses. Therefore, instead of interviewing the teachers, we interviewed the students in order to have direct and honest answers. Additionally, we have believed that the students would answer our questions directly and honestly because they do not have anything to lose or to afraid. In this paper, we conducted unstructured interviews (not formal) with 20 students over Jul-Aug 2021. The participants of this research were only male students representing in two different academic levels; 10 students in middle school and 10 students in high school. In each level/stage, we interviewed 10 students with some questions. The interviews were conducted face-to-face, and without recording the conversations in order to put the participants in comfortable situation. In fact, unstructured interviews have positive impact on the interviewees because they can show their thoughts and ideas freely. In addition to that, data were collected from the participants through multiple questions during the conversations. All questions have been asked about English classes and teachers. For example, do the students like English classes? Do their teachers speak English or Arabic in English classes? Do the students understand the value of learning English language? Do their teachers provide any activities in English classes for the sake of learning English? On the other hand, the answers were collected based on qualitative method which is Thematic Analysis (TA).

\subsection{Thematic Analysis}

Thematic Analysis is a qualitative method. This method is used to analyze qualitative data. For example, this method can be conducted to collect data from texts, interview transcripts, survey responses, etc. Researchers use this effective method to reach some results that indicate solutions to research problems. Furthermore, Thematic Analysis is an effective method for researchers who seek to discover something about participants' opinions, 
ideas, experience, thought, and knowledge. In fact, this study is based on a deductive method because certain outcomes were predicted based on prior knowledge of Saudi schools and Saudi instructors. The steps that used after interviews to identify the themes were coding, generating themes, reviewing themes, defining and naming themes, and finally show the outcomes of those interviews.

\section{Analysis and Discussion}

Based on unstructured interviews with the participants, we end up with main themes that can be noticeable as follows; (1) teachers use English only at the beginning of the lecture, (2) teachers explain the difficult points in Arabic instead of English, and (3) teachers speak Arabic when the lecture ends before its regular time.

\subsection{Teachers Use English only at the Beginning of the Lecture}

The participants claimed that Saudi teachers of English language speak English only at the beginning of the class. They claimed that the Saudi teachers avoid speaking English all the time to cover their weaknesses in the language. In addition, the Saudi teachers of English language are struggling with the use of English language, therefore, the Saudi students will be affected in their performance. In fact, this is one of the main reasons that proves that teachers of English language in Saudi Arabia are considered as prominent problem of learning English language.

\subsection{Teachers Explain the Difficult Points in Arabic Instead of English}

The majority of participants explained that the other part of teachers can speak English fluently, however, once the students stopped to understand a crucial point, they explain it in Arabic in order to make it easy and clear for the students. However, we argue that using the mother tongue to explain an important point is just a temporary solution that leads to bad consequences. In addition to that, using the mother tongue to facilitate the hard points will not help the students to speak and understand the English language in an appropriate way. Because students will think in Arabic instead of English, they will ask the teachers to explain every hard point in Arabic, and the lecture will lose its main target which is using English language in the class as a full-time.

\subsection{Teachers Speak Arabic When the Lecture's Objectives End Before Its Regular Time}

Most of the participants have admitted that teachers use English to explain the goals of the lecture, however, once they finish the goals, they speak Arabic to the end of the lecture. Therefore, the students will allow themselves to speak Arabic to the end of the lecture. In fact, we argue that teachers of English language should use English language full-time in English classes regardless of all the excuses. On the other hand, if the objectives of the lecture have reached, teachers should talk about other topics that can be familiar to the students in order to encourage them to speak English as they can. For example, speak about sports and its fields, well known movies and/or series, and video games, etc. In fact, speaking Arabic in Saudi English classes is well-known and clear. This action reduces the Saudi students' efficiency in English language at all levels.

\subsection{Students do not Understand the Value of Learning English Language}

We discovered that the majority of Saudi students do not grasp the importance of studying English based on their replies and opinions throughout the interviews. They do not realize how English is important and essential for their future. In addition to that, it may be hard to comprehend how English is crucial to their career's journey. In fact, all these wrong ideas about English have grown up with the students because of their teachers. Teachers do not speak English in English classes, they do not explain the importance of English, and they do not do any practices to encourage the students to participate the lecture. Therefore, how can students understand the value of English? How can they realize that English will be an important key for their future? In order to find answers to these concerns, our instructors should first confess that they are part of the problem, and they should understand the importance of English before teaching it.

\section{Conclusion}

In this article, we argue that the lack of qualified English teachers in Saudi classes is the main reason that prevents and obstructs the Saudi students' ability to learn, think, and advance in English language. Because of this, unstructured interviews have conducted with 20 students; 10 in high schools and 10 middle schools. In fact, instead of interviewing teachers, we interviewed students in order to obtain real answers. In this paper, a qualitative method has used to analyze the outcomes of the interviews which is Thematic Analysis (TA). On other hand, the participants have shared their fears of studying English. They believed that teachers in Saudi Arabia are still need practice and experience to be qualified for teaching English. They claimed that the majority of the English teachers in Saudi Araba are speaking Arabic in English classes. In addition to that, they described how teachers speak English only at the beginning of the class, but they switch the language from English to 
Arabic to the end of the class as a permanent habit. Moreover, they explained how teachers explain complicated items and concepts in Arabic instead of English as an appropriate solution. However, these techniques can only serve temporary goals, but will cause negative effects on the students' competence and performance in learning English language. All of the issues mentioned above that are connected to instructors are impeding students' growth. In fact, students described how they could not speak English language even though they understand English. To avoid that, there should be real interaction between the teachers and the students in the classrooms. In light of these claims and consequences, we ask the Saudi Ministry of Education for urgent intervention to take crucial steps to ensure that Saudi students learn English in the right way. We ask to organize regular training to improve Saudi teachers especially English teachers. We seek to have daily programs and courses whether online or face-to-face to help teachers to be qualified teachers. On the other hand, we advise that Saudi teachers should be aware of effective methods of teaching. We urge to stop using old methods and start to use modern or effective methods. We ask to understand the value of technology and try to use it for the sake of improving the environment of learning. We advise to stop use Arabic in English classes under any circumstances especially in primary schools. In fact, if we had qualified teachers for teaching English, we would have a positive impact on the students' performance and competence.

\section{References}

Al-Seghayer, K. (2014). The four most common constraints affecting English teaching in Saudi Arabia. International Journal of English Linguistics, 4(5), 17. https://doi.org/10.5539/ijel.v4n5p17

Al-Sobhi, B. M. S., \& Preece, A. S. (2018). Teaching English speaking skills to the Arab students in the Saudi school in Kuala Lumpur: Problems and solutions. International Journal of Education and Literacy Studies, 6(1), 1-11. https://doi.org/10.7575/aiac.ijels.v.6n.1p.1

Boumová, V. (2008). Traditional vs. modern teaching methods: Advantages and disadvantages of each. Masarykova univerzita, Filozofická fakulta.

Elyas, T., \& Mahboob, A. (2014). English in the Kingdom of Saudi Arabia. World Englishes, 33(1), 128-142. https://doi.org/10.1111/weng.12073

Hamad, M. M. (2013). Factors Negatively Affect Speaking Skills at Saudi Colleges for Girls in the South. English Language Teaching, 6(12), 87-97. https://doi.org/10.5539/elt.v6n12p87

Swan, M., \& Smith, B. (2001). Learner English: A Teacher's Guide to Interference and Other Problems. Cambridge University Press. https://doi.org/10.1017/CBO9780511667121

\section{Copyrights}

Copyright for this article is retained by the author(s), with first publication rights granted to the journal.

This is an open-access article distributed under the terms and conditions of the Creative Commons Attribution license (http://creativecommons.org/licenses/by/4.0/). 